\title{
Micro and macro vascular complications in people with type 2 diabetes mellitus in outpatient care
}

\author{
Complicações micro e macrovasculares em pessoas com Diabetes Mellitus tipo 2 em \\ atendimento ambulatorial
}

Valéria Cristina Delfino de Almeida ${ }^{1}$, Samila Torquato Araújo ${ }^{2}$, Francisca Diana da Silva Negreiros ${ }^{3}$, Maria Isis Freire de Aguiar ${ }^{4}$, Tatiana Rebouças Moreira ${ }^{5}$, Ana Paula Plácido Crispim ${ }^{6}$

Objective: to analyze the factors related to micro and macro vascular complications in people with type 2 diabetes mellitus. Methods: a documentary survey of 134 patients with type 2 diabetes mellitus. Bivariate statistical analysis (Pearson's Chi-square test and Fisher's test), with statistical significance if $p<0.05$. Results: the frequency of micro vascular complications was 50.7\%, and retinopathy was the most found (61.7\%). There was a statistical association between the group with more than 10 years of disease and the presence of retinopathy. Cardiopathy was one of the most frequent macro vascular complications (69.0\%). Regarding the use of insulin therapy in mono therapy, there was significance in the presence of nephropathy and vascular disease. Conclusion: results with statistical significance related to the appearance of complications with disease time, highlighting the presence of diabetic retinopathy. It was verified that the lower the schooling, the greater the onset of vascular disease.

Descriptors: Diabetes Mellitus, Type 2; Diabetes Complications; Public Health; Risk Factors; Health Care (Public Health).

Objetivo: analisar os fatores relacionados às complicações micro e macrovasculares em pessoas com Diabetes Mellitus tipo 2. Métodos: pesquisa documental, com 134 prontuários de pessoas com Diabetes Mellitus tipo 2. Realizada análise estatística bivariada (Qui-quadrado de Pearson e teste de Fisher), com significância estatística se p<0,05. Resultados: a frequência de complicações microvasculares foi 50,7\%, sendo a retinopatia a mais encontrada $(61,7 \%)$. Houve associação estatística entre o grupo com mais de 10 anos de doença e a presença de retinopatia. A cardiopatia foi uma das complicações macrovasculares mais frequentes $(69,0 \%)$. Quanto à utilização de insulinoterapia em monoterapia, houve significância na presença de nefropatia e doença vascular. Conclusão: resultados com significância estatística relacionaram o surgimento de complicações com o tempo de doença, destacando-se a presença de retinopatia diabética. Verificou-se que quanto menor a escolaridade, maior é o surgimento da doença vascular.

Descritores: Diabetes Mellitus Tipo 2; Complicações do Diabetes; Saúde Pública; Fatores de Risco; Atenção à Saúde.

\footnotetext{
${ }^{1}$ Universidade Federal do Ceará. Fortaleza, CE, Brazil. 


\section{Introduction}

Diabetes is a disease with a high prevalence worldwide, which is often associated with other comorbidities of a chronic character, such as hypertension. Currently, non-communicable diseases are responsible for $66.0 \%$ of the burden of diseases in Brazil and, among them; Diabetes Mellitus stands out for morbidity and mortality. Thus, studies on diabetes have been carried out and continue to arouse interest, and through them, measures and care can be sought that encompass the various aspects of the disease $\mathrm{e}^{(1)}$. The two major types are Type 2 Diabetes Mellitus, which accounts for 85 to $90.0 \%$ of cases, and type 1 which corresponds to 5 to $10.0 \%{ }^{(2)}$.

Diabetes Mellitus is one of the largest global health emergencies of the 21st century, and in addition to the 415 million adults currently estimated to have Diabetes, there are 24.8 million adults with impaired glucose tolerance, which puts them at risk of developing the disease in the future. Brazil is among the top ten countries with the highest prevalence of Diabetes, with 14.3 million adults with this disease ${ }^{(3)}$.

It is a public health problem due to high morbidity, disability, premature mortality and public costs involved in treatment and complications ${ }^{(4)}$. Recent estimates of the costs of outpatient treatment of persons with Diabetes through the Brazilian Unified Health System are of the order of US $\$ 2,108.00$ per patient, of which US $\$ 1,335.00$ are related to direct $\operatorname{costs}^{(5)}$.

Several factors contribute to the involvement and increase of the incidence of Diabetes Mellitus; among them are the aging of the population, growing urbanization, the adoption of unhealthy lifestyles, as well as inadequate diet and obesity, aspects that favor significant increase in the prevalence of Diabetes worldwide ${ }^{(6)}$.

The complications related to this disease can be classified as acute and chronic, and may be motivated by inadequate treatment and blood glucose levels that are incompatible with the recommended goals ${ }^{(7)}$. Among the chronic complications are the micro and macro vascular levels. The most common micro vascular aggravations are: neuropathy, retinopathy, nephropathy and ischemia. The development of ischemic heart disease, cerebrovascular disease and peripheral vascular disease is highlighted at the macro vascular level(8).

When the patient with Diabetes Mellitus cannot obtain good glycemic control and presents risk factors for complications, it is referred to specialized care in secondary or tertiary referral units, thus guaranteeing greater treatment resolution. In this context, referral protocols were created to assist in the evaluation of requests and, among the demand diagnoses, Diabetes Mellitus is in the most prevalent reasons for the specialty Endocrinology ${ }^{(9)}$.

It is believed that the production of information regarding the prevalence and factors associated with micro and macro vascular complications can increase the knowledge about the health profile of people with Diabetes Mellitus, as well as stimulate the formulation of strategies and policies aimed at this condition.

Therefore, this article is aimed at analyzing the factors related to micro and macro vascular complications in people with Type 2 Diabetes Mellitus.

\section{Methods}

This documentary research was carried out at the endocrinology clinic of a reference hospital in Fortaleza, Ceará, Brazil. Data collection occurred between September and December 2016.

The population was made up of people with Type 2 Diabetes Mellitus and the sample totaled 134 patients. A person with the diagnosis of Type 2 Diabetes Mellitus and in regular follow-up was considered as inclusion criteria. Exclusion criteria were considered as users who abandoned treatment, lacked the last consultations, as well as those who were not located for more than two attempts.

The information was collected through the review of the patients' medical records, with the completion of a pre-structured instrument produced by 
the researcher himself, containing questions regarding sociodemographic data (sex, color, marital status, education, religion, profession/occupation) cardiovascular disease, respiratory disease, renal disease and obesity), life habits (smoking and alcoholism), time of diagnosis of Diabetes Mellitus, complications due to Diabetes Mellitus (acute and chronic micro vascular and macro vascular complications), hypertension, dyslipidemia, ), periodicities of the consultations and pharmacological treatment (hypoglycemic, antihypertensive, antilipidemic and insulin therapy).

The data were organized in Excel spreadsheet Microsoft Windows 2013 and analyzed with the software Statistical Package for the Social Sciences, version 22. We performed tests of association between the independent variables and the variable of interest (micro and macro vascular complications from Diabetes), by means of univariate analysis (Pearson's Chi-square and Fisher's test), with statistical significance if $\mathrm{p}<0.05$. The results were structured into tables for presentation and discussion, according to the pertinent literature.

The study complied with the formal requirements contained in national and international standards for research involving human beings.

\section{Results}

Among the 134 charts analyzed, the average age was 63 years $( \pm 12.33), 68.6 \%$ (92) female, $25.3 \%$ (34) dark skinned, 44.7\% (60) married, 25.3\% (34) retired and $63.4 \%$ (85) with more than 10 years of illness. Regarding schooling, $10.4 \%$ (14) did not complete elementary school and $62.6 \%$ (84) had no recor$\mathrm{ds}$ in the medical records. Regarding religion, $60.4 \%$ (81) did not have the information recorded and $30.6 \%$ (41) reported being Catholic.

Concerning the habits of life, only 7.4\% (10) were smokers and 5.9\% (8) alcoholics. Dyslipidemia $(88.0 \% / 118)$, followed by arterial hypertension (87.3\%/117) and cardiovascular diseases (33.5\%/45) were noted as comorbidities. As for the association of comorbidities among the patients, $17.2 \%$ (23) had arterial hypertension and dyslipidemia, 12.7\% (17) had arterial hypertension, dyslipidemia and chronic kidney disease, and 10.4\% (14) hypertension, dyslipidemia and cardiovascular disease. The frequency of follow-up with specialization in endocrinology was every three months $(35.8 \% / 48)$.

The micro and macro vascular categories are not mutually exclusive, since one patient had more than one comorbidity. Regarding the complications, acute micro vascular presented a rate of $23.8 \%$ (32), with emphasis on episodes of hypoglycemia (96.8\%/31, CI=90.7-100). Chronic complications presented a prevalence of $50.7 \%$ (68), of which $61.7 \%$ (42; $\mathrm{CI}=50.1-72.2$ ) had retinopathy, $48.5 \%$ (33; $\mathrm{CI}=36.6-60,3)$ renal involvement and $57.3 \%$ (39; $\mathrm{CI}=45.5-69.0)$ symmetrical sensorimotor neuropathy. It was verified that $40.3 \%$ (54) presented macro vascular complications, among them the heart disease $(69.0 \% 38, \mathrm{CI}=56.6-81.3)$, followed by peripheral vascular disease (31.4\%/17; $\mathrm{CI}=19.0-43.7)$. Of these, $22.2 \%$ (12; $\mathrm{CI}=11.1-43.7$ ) suffered a stroke, according to Table 1.

Table 1 - Micro and macro vascular complications of people with Type 2 Diabetes Mellitus

\begin{tabular}{lcc}
\hline Variables & $\mathbf{n}(\mathbf{\%})$ & CI 95\%** \\
\hline Microvascular complications * & & \\
Acute (n=32) & & \\
Hypoglycemia & $31(96.8)$ & $90.7-100.0$ \\
Hyperosmolar hyperglycemic state & $1(3.2)$ & $0.0-9.1$ \\
Chronic (n=68) & & \\
Retinopathy & $42(61.7)$ & $50.1-72.2$ \\
Diabetic nephropathy & $33(48.5)$ & $36.6-60.3$ \\
Symmetrical sensorimotor neuropathy & $39(57.3)$ & $45.5-69.0$ \\
Macrovascular complications ${ }^{*}(\mathrm{n}=54)$ & & \\
Peripheral vascular disease & $17(31.4)$ & $19.0-43.7$ \\
Diabetic foot & $11(20.3)$ & $9.5-31.0$ \\
Ischemic heart disease & $38(69.0)$ & $56.6-81.3$ \\
Stroke & $12(22.2)$ & $11.1-33.2$ \\
\hline Categories are not mutually exclusive;*CI= Confidence interval
\end{tabular}


The association of sociodemographic variables with micro and macro vascular complications did not show statistically significant results, except for the presence of peripheral vascular disease, which showed association with schooling $(\mathrm{p}=0.030)$.

The analysis of the drug treatment showed the use of hypoglycemic agents in $85.8 \%$ (115) of the patients, standing out the biguanide class, with $85.0 \%$ (114). A total of $82.8 \%$ (111) used antihypertensive therapy, the main drug being angiotensin receptor blocker, one (57.5\%/77). In antilipidemic therapy, $82.0 \%$ (110) used statins and only 7.5\% (10) fibrates. The use of acetylsalicylic acid was $68.0 \%$ (83). Regarding insulin therapy $(75.4 \% / 101)$, those using intermediate-acting insulin corresponded to $92.0 \%$ (93); fast acting insulin, 71.3\% (72); and used analogues, $16.8 \%$ (17).

The time of diagnosis of complications was associated to the group with more than 10 years of disease and the appearance of retinopathy $(p=0.003)$, according to Table 2.

Table 2 - Occurrence of micro and macro vascular complications by time of diagnosis

\begin{tabular}{|c|c|c|c|c|}
\hline \multirow[t]{2}{*}{ Variables } & $\begin{array}{c}<5 \\
\text { (years) } \\
(n=25)\end{array}$ & $\begin{array}{l}\geq 5-10 \\
(\text { yaers }) \\
(n=24)\end{array}$ & $\begin{array}{c}>10 \\
\text { (yaers) } \\
(n=85)\end{array}$ & $\mathbf{p}^{* *}$ \\
\hline & n (\%) & n (\%) & n (\%) & \\
\hline \multicolumn{5}{|l|}{ Microvascular * } \\
\hline Nephropathy & $2(18.2)$ & $4(16.0)$ & 27 (17.3) & 0.280 \\
\hline Retinopathy & $1(9.1)$ & $5(20.0)$ & 36 (23.1) & 0.003 \\
\hline $\begin{array}{l}\text { Symmetrical sensorimotor } \\
\text { neuropathy }\end{array}$ & $5(45.4)$ & $5(20.0)$ & 29 (18.6) & 0.852 \\
\hline \multicolumn{5}{|l|}{ Macrovascular * } \\
\hline Vascular disease & - & $1(4.0)$ & $16(10.2)$ & 0.122 \\
\hline Diabetic foot & - & - & $11(7.1)$ & 0.185 \\
\hline Cardiopathy & $\begin{array}{c}3 \\
(27.3)\end{array}$ & $8(32.0)$ & 27 (17.3) & 0.487 \\
\hline Stroke & - & $2(8.0)$ & $10(6.4)$ & 0.100 \\
\hline
\end{tabular}

The analysis of the correlation of the complications of the disease with respect to the treatment used showed an association between the use of insulin and the appearance of micro vascular complications, with emphasis on nephropathy $(\mathrm{p}=0.021)$ and vascular disease $(p=0.001)$ (Table 3).

Table 3 - Presence of micro vascular complications according to drug treatment

\begin{tabular}{lcccc}
\hline \multirow{2}{*}{ Variables } & $\begin{array}{c}\text { Hypoglyce- Insulin } \\
\text { mic Oral } \\
\text { therapy }\end{array}$ & $\begin{array}{c}\text { Combina- } \\
\text { tion The- } \\
\text { rapy }\end{array}$ & $\mathbf{p}^{*}$ \\
\cline { 2 - 5 } & $\mathbf{n ( \% )}$ & $\mathbf{n ( \% )}$ & $\mathbf{n ( \% )}$ & \\
\hline Nephropathy (n=33) & $2(25.0)$ & $11(78.6)$ & $20(43.5)$ & 0.021 \\
Retinopathy (n=42) & $3(37.5)$ & $12(85.7)$ & $27(58.7)$ & 0.067 \\
Symmetric neuropathy (n=39) & $6(75.0)$ & $7(50.0)$ & $26(56.5)$ & 0.604 \\
Vascular disease (No.=17) & $6(18.2)$ & $8(42.1)$ & $6(7.3)$ & 0.001 \\
Diabetic foot (n=11) & $2(18.2)$ & $4(33.3)$ & $5(16.1)$ & 0.424 \\
Cardiopathy (n=38) & $6(54.5)$ & $9(75.0)$ & $23(71.9)$ & 0.613 \\
Stroke (n=12) & $4(36.4)$ & $3(25.0)$ & $5(16.1)$ & 0.292 \\
\hline *Fisher's Exact Test: $\mathrm{p}<0.05$ & & & &
\end{tabular}

\section{Discussion}

The study presents as a methodological limitation the use of data contained in medical records, since there was no information obtained directly from those involved, thus highlighting the subjectivity of the documents. In addition, the restrictions of the research are related to the deficiency of information in medical records, with incomplete filling and, sometimes, illegible letters. It was evident the lack of registration of professionals regarding the consultations, the failure that makes it impossible to systematize and evaluate the assistance.

Diabetes Mellitus has a high rate of associated morbidity and mortality, mainly due to micro and macro vascular complications. Although it may have repercussions on practically all organs, it is the kidneys, eyes, peripheral nerves and vascular system that are most frequently studied, since they are related to the clinically more severe complications of the disease $^{(10)}$.

The prevalence of chronic micro vascular complications in this study was high (50.8\%); the 
same was observed in a cross-sectional study of 318 patients with type 2 diabetes mellitus and similar age, in which $53.8 \%$ developed micro vascular complications $^{(11)}$. The high rate of complications is directly related to the fact that the service in which the research was performed is a reference in attending this clientele.

When considering micro vascular complications in isolation, the prevalence of diabetic retinopathy identified (61.7\%) was higher than that found in a retrospective study in four health centers, performed with 161 patients with Type 2 Diabetes Mellitus, whose occurrence of nephropathy, $37.3 \%$, was more frequent ${ }^{(12)}$.

In this study, participants with more than 10 years of disease presented retinopathy more often, corroborating with another study that affirmed the greater probability of complications in the retina, with high disease duration in up to $30.0 \%$ of people with Type 2 Diabetes Mellitus ${ }^{(13)}$. In addition, they may have had years of Diabetes without confirmation, then the ophthalmologic examination is indicated at the time of diagnosis ${ }^{(14)}$. The analysis of complications by time of disease showed that the group with more than 10 years presented a higher frequency also of neuropathy.

The occurrence of diabetic foot was present in $20.4 \%$ of patients with a diagnosis time greater than 10 years. This data corroborates a study carried out in an interdisciplinary diabetes outpatient clinic, whose average time of diagnosis of the patients was 15 years $^{(15)}$.

With respect to complications, vascular disease was associated with educational level, as well as a study that associated lower education with poor therapeutic adherence in chronic diseases, thus favoring the incorrect follow-up of the treatment, resulting in ineffective glycemic control, which in turn, contributes to the appearance of complications ${ }^{(16)}$.

Among macro vascular complications, heart disease ranked second in terms of prevalence, which in turn is strongly associated with mortality and morbi- dity in diabetic populations ${ }^{(17)}$. This incidence ranged from 14.3 to 46.9 cardiovascular disease events in a study with 1,000 people followed up for one year, considering the average age of the studied populations from 57 to 64 years old ${ }^{(4)}$.

Most people with Diabetes Mellitus (88.0\%) had dyslipidemia, a fact that is associated with chronic hyperglycemia, increasing the chance of developing cardiovascular complications. Changes in lipid metabolism are frequent in these patients. In a study that evaluated the clinical and laboratorial profile and vascular compromise in patients with type 2 diabetes mellitus, the presence of dyslipidemia (80.0\%) was significant, given reinforcement in this study, in which patients presented some dyslipidemia and used therapy antilipidemic ${ }^{(18)}$.

The association between arterial hypertension and Diabetes Mellitus was prevalent, corroborating with another study, in which approximately $40.0 \%$ of patients with a recent diagnosis of type 2 diabetes mellitus have arterial hypertension ${ }^{(19)}$. However, they often had more than two associated comorbidities, among them, $17.2 \%$ had arterial hypertension and dyslipidemia, both of which constitute a risk for cardiovascular disease, and their control reduces the risk of events substantially, according to a clinical trial performed with 12,705 participants, where the use of therapy for both showed an association with a significantly lower rate of cardiovascular events ${ }^{(20)}$.

Statistical association was observed in the use of insulin alone with nephropathy and vascular disease when analyzing the therapeutic regimens used. Corroborating this finding, another study showed the same significant association between insulin use and the occurrence of neuropathy, considering the relationship of this treatment with the better glycemic control and, consequently, the reduction of complications of the disease ${ }^{(11)}$.

However, it is questioned about the combination therapy to improve glycemic control, a fact present in a position of the American Diabetes Association, which exposes that the therapeutic effects of 
insulin would become potentially more active, when associated to the effects of the different hypoglycemic agents in the main alterations pathophysiological factors that characterize type 2 diabetes mellitus, such as insulin resistance, increased pancreatic insulin secretion, and decreased hepatic glucose secretion ${ }^{(14)}$. The study population was predominantly elderly and derived from primary care referrals because it contained insulin resistance, evidenced by glycemic decompensation and, often, established complications.

Therefore, the analysis of such associations in individuals with Type 2 Diabetes Mellitus underscores the importance of identifying the problems faced by the population, in which care is provided, so that preventive interventions and monitoring can be performed by theoretical basis and under constant evaluation.

\section{Conclusion}

Results with statistical significance related the appearance of complications with the disease time, highlighting the presence of diabetic retinopathy. It was verified that the lower the schooling, the greater the onset of vascular disease.

\section{Collaborations}

Almeida VCD contributed in designing, analyzing and interpreting the data and in the writing the article. Araújo ST, Negreiros FDS, Aguiar MIF, Moreira TR and Crispim APP contributed in the relevant critical revision of the intellectual content and final approval of the version to be published.

\section{References}

1. Mielczarski RG, Costa JSD, Olinto MTS. Epidemiologia e organização de serviços de saúde: diabetes mellitus numa comunidade de Porto Alegre. Ciênc Saúde Coletiva. 2012; 17(1):71-8. doi: http://dx.doi.org/10.1590/ S1413-81232012000100010
2. Vilar L, Castellar E, Moura E, Leal E, Machado AC, Teixeira L, et al. Endocrinologia clínica. Rio de Janeiro: Guanabara Koogan; 2013.

3. International Diabetes Federation. IDF Diabetes Atlas. Brussels/Belgium: International Diabetes Federation [Internet]. 2015 [cited 2017 Mar. 30]. Available from: http://www.idf.org/diabetesatlas

4. Oliveira DM, Schoeller SD, Hammerschmidt KSA, Vargas MAO, Girondi JBR. Nursing staff knowledge in relation to complications of diabetes mellitus in emergency services. Acta Paul Enferm. 2014; 27(6):520-5. doi: http://dx.doi. org/10.1590/1982-0194201400085

5. Sociedade Brasileira de Diabetes. Diretrizes. Tratamento e acompanhamento do Diabetes Mellitus. São Paulo: Sociedade Brasileira de Diabetes; 2016.

6. Palmeira CS, Pinto SR. Perfil epidemiológico de pacientes com diabetes mellitus em Salvador, Bahia, Brasil (2002-2012). Rev Baiana Enferm. 2015; 29(3):240-9. doi: http://dx.doi.org/10.18471/ rbe.v29i3.13158

7. Gomides DS, Villas-Boas LCG, Coelho ACM, Pace AE. Self-care of people with diabetes mellitus who have lower limb complications. Acta Paul Enferm. 2013; 26(3):289-93. doi: http://dx.doi. org/10.1590/S0103-21002013000300014

8. Bertoldi AD, Kanavos P, França GVA, Carraro A, Tejada CAO, Hallal PC, et al. Epidemiology, management, complications and costs associated with type 2 diabetes in Brazil: a comprehensive literature review. Global Health. 2013; 9(1):1-12. doi: https://doi.org/10.1186/1744-8603-9-62

9. Ministério da Saúde (BR). Protocolos de encaminhamento da atenção básica para atenção especializada: endocrinologia e nefrologia. Brasília: Ministério da Saúde; 2016.

10. Marquesa AR, Brito I. Clinical spectrum of musculoskeletal manifestations of diabetes mellitus. Rev Port Endocrinol Diabetes Metabol. 2016; 11(2):307-13. doi: https://doi.org/10.1016/j. rpedm.2016.02.011

11. Santos ADL, Cecílio HPM, Teston EF, Arruda GOD, Peternella FMN, Marcon SS. Microvascular complications in type 2 diabetes and associated factors: a telephone survey of self-reported morbidity. Ciênc SaúdeColetiva.2015;20(3):761-70. doi:http://dx.doi.org/10.1590/1413-81232015203.12182014 
12. Saraiva JFK, Hissa MN, Felício JS, Cavalcanti CAJ, Saraiva GL, Piha T et al. Diabetes mellitus no Brasil: características clínicas, padrão de tratamento e custos associados ao cuidado da doença. J Bras Econ Saúde. 2016; 8(2):80-90. doi: https://doi. org/10.21115/JBES.v8.n2.p80-90

13. Nentwich MM, Ulbig MW. Diabetic retinopathyocular complications of diabetes mellitus. World J Diabetes. 2015; 6(3):489-99. doi: https://doi. org/10.4239/wjd.v6.i3.489

14. American Diabetes Association. Comprehensive medical evaluation and assessment of comorbidities. Diabetes Care. 2017; 40(supl1):2532. doi: https://doi.org/10.2337/dc17-S006

15. Thomazelli FCS, Machado CB, Dolçan KS. Análise do risco de pé diabético em um ambulatório interdisciplinar de diabetes. Rev AMRIGS [Internet]. 2015 [citado 2017 jan. 22]; 59(1):104. Disponível em: http://www.amrigs.com.br/ revista/59-01/02_1436_Revista\%20AMRIGS.pdf

16. Tavares NUL, Bertoldi AD, Mengue SS, Arrais PSD, Luiza VL, Oliveira MA, et al. Factors associated with low adherence to medicine treatment for chronic diseases in Brazil. Rev Saúde Pública. 2016; 50(supl2):10. doi: http://dx.doi.org/10.1590/ s1518-8787.2016050006150
17. Leon BM, Maddox TM. Diabetes and cardiovascular disease: epidemiology, biological mechanisms, treatment recommendations and future research. World J Diabetes. 2015; 6(13):1246-58. doi: https://doi.org/10.4239/wjd.v6.i13.1246

18. Chaves RL, Anghebem-Oliveira MI. Perfil clínicolaboratorial e comprometimento vascular em pacientes com diabetes mellitus tipo 2. Arq Ciênc Saúde UNIPAR. 2016; 20(1):59-65. doi: https:// doi.org/10.25110/arqsaude.v20i1.2016.5467

19. Malachias MVB, SouzaWKSB, PlavnikFL, Rodrigues CIS, Brandão AA, Neves MFT, et al. 7th Brazilian Guideline of Arterial Hypertension: chapter 3 - clinical and complementary assessment. Arq Cienc Saúde UNIPAR. 2016; 107(3):1-82. doi: http://dx.doi.org/10.5935/abc.20160153

20. Salim Y, Phil D, Lonn E, Prem P, Bosch J, LópezJaramillo P, et al. Blood-Pressure and Cholesterol Lowering in Persons without Cardiovascular Disease. N Engl J Med. 2016; 374:2032. doi: https://doi.org/10.1056/NEJMoa1600177 